\title{
Obstruktif uyku apne sendromu'nun kadın cinsel fonksiyonu ve memnuniyete olan etkisi
}

\section{The Effect of Obstructive Sleep Apnea Syndrome to the Female Sexual Function and Satisfaction}

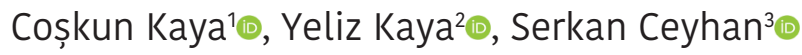

öz

AMAC:: Obstruktif uyku apne sendromu (OUAS)'nun mevcudiyeti ve şiddetinin kadın cinsel fonksiyonuna ve cinsel memnuniyeti üzerine etkisi olup olmadığını göstermeye çalıştık.

GEREÇ ve YÖNTEM: Ocak-Haziran 2018 tarihleri arasında Eskişehir Devlet Hastanesi Uyku Bozukluğu Laboratuarı'na horlama ve gece nefes tıkanıklığı nedeniyle başvuran kadın hastalar çalışmaya dahil edildi. Hastalara cinsel fonksiyonlarını değerlendirmek için Kadın Cinsel Fonksiyon İndeksi (KCFÍ), cinsel memnuniyetlerini değerlendirmek için Kadın Cinsel Memnuniyet Ölçeği (KCMÖ) ve Epworth Uykululuk Ölçeği doldurtulduktan sonra, tüm gece polisomnografi testi uygulandı. Hastalar Apne-Hipopne İndeksi'ne (AHI) göre normal (<5) hafif (5-15) ve orta-ciddi $(>15)$ olarak üçe ayrıldı, OUAS saptanmayan kadın hastalar kontrol grubuna dahil edildi.

BULGULAR: Çalışmaya katılmayı kabul eden, kriterlere uyan 18 hasta kontrol grubu (grup 1); hafif OUAS olan 8 hasta grup 2, orta-ağır OUAS olan 16 hasta grup 3 olarak tespit edildi. Grup 1'in ortalama yașı $39,27 \pm 7,84$ yıl iken grup 2 ve 3 'te sırası ile ortalama yaș $44 \pm 6,27$ ve $41,81 \pm 4,57$ yl bulundu ( $p>0,05)$. Grup 1, 2 ve 3 'teki hastaların KCFI toplam puanları sirasiyla $19,64 \pm 7,78,15,87 \pm 8,34$ ve $19,08 \pm 9$, 56 bulunmuş, toplam puanlar arasında anlamlı bir fark bulunmamıştır ( $>0,05)$. Hem 3 grup birlikte hem de ayrı ayrı birbiriyle karşılaşııııldıklarında cinsel disfonksiyon sıklığı ve KCFİ alt parametre puanları açısından istatistiksel bir fark saptanmamıştır ( $>>0,05)$. Grup 1'deki hastaların KCMÖ toplam puanları $76,11 \pm 18,97$, grup 2 için $68,5 \pm 18,59$ ve grup 3 için $80,65 \pm 18,03$ olduğu tespit edildi. Toplam puanlar ve alt parametre puanları hem 3 grup birlikte hem de ayrı ayrı birbiriyle karșilaștırıldıklarında istatistiksel olarak anlamlı fark bulunamamıştır. OUAS tanısı konan 24 hastanın KCFİ toplam ve alt parametre puanları ile KCMÖ toplam ve alt parametre puanları korelasyon analizi ile değerlendirildiğinde KCMÖ’nin endişe parametreleri haricinde iki ölçeğin hem toplam hem de alt parametre puanları arasında istatistiksel olarak birbiri ile ilişkili olduğu saptanmıştır $(\mathrm{p}<0,05)$.

SONUCุ: OUAS'li kadınlarda cinsel fonksiyonların ve memnuniyet düzeylerinin paralel oranda olumsuz etkilendiği saptanmıștır. Bu nedenle, kadın cinsel sağlığı değerlendirmelerinde cinsel fonksiyonları ile beraber cinsel memnuniyet de göz önünde bulundurulmalıdır.

Anahtar Kelimeler: Kadın cinsel işlev bozukluğu, kadın cinsel memnuniyeti, obstruktif uyku apne sendromu

${ }^{1}$ Eskišehir Sehir Hastanesi, Üroloji Bölümü, Eskisehir, Türkiye

${ }^{2}$ Eskişehir Osmangazi Üniversitesi, Sağlık Bilimleri Fakültesi, Doğum ve Kadın

Hastalıkları Hemşireliği Bölümü, Eskişehir, Türkiye

${ }^{3}$ Eskişehir Şehir Hastanesi, KBB Bölümü, Eskişehir, Türkiye

Yazışma Adresi/ Correspondence:

Op.Dr. Çoşkun Kaya

Büyükdere M Cevahir S Gülșen Apt. 21/9 26000 Eskişehir, Türkiye

Tel. +905064434154

E-mail: coskun_kaya2008@yahoo.com

Gelis/ Received: $\quad 27.09 .2018$

Kabul/ Accepted: $\quad 30.11 .2018$
ABSTRACT

OBJECTIVE: To investigate the relation with the existence and severity of obstructive sleep apnea syndrome (OSAS) and sexual functions and satisfactions of females who have been diagnosed with OSAS.

MATERIAL and METHODS: Female patients who have been investigated with a complaint of snoring and apnea and scheduled to undergo full night polysomnography in Eskisehir State Hospital between January and June 2018 were the subjects of this study. Patients were asked to fill Epworth Sleepiness Scale (ESS), Female Sexual Function Index (FSFI) and The Sexual Satisfaction Scale for Women (SSS-W) before sleep study in order to assess their sleepiness, sexual functions and sexual satisfaction respectively. Patients were grouped as: simple snorers (control group; group 1), mild OSA (apnea-hypopnea index (AHI): 5-15; group 2) and moderate/severe OSA (AHI >15; group 3) according to their AHI.

RESULTS: 18,8 and 16 patients, who were willing to participate to the study and met the inclusion criteria, were groups as control, mild OSA and moderate/severe OSA respectively. Age distributions of groups were as $39.27 \pm 7.84,44 \pm 6.27$ and $41.81 \pm 4.57$ years for group 1,2 and 3 respectively $(p>0.05)$. Total FSFI points of each groups were similar ( $p>0.05)$. There were no statistically differences in the prevalence of sexual dysfunction and FSFI aspects' scores between all three groups and when the all groups compared between each other $(p>0.05)$. Total SSS-W points of each groups were similar ( $p>0.05)$. When the total and aspects' points of FSFI and the total and aspects' points of SSS-W were evaluated by correlation analysis in the 24 patients diagnosed OSAS, both two scales' total and aspects' points were correlated between each other except the 'concern' aspects in the SSS-W ( $<<0.05)$.

CONCLUSION: It was found that sexual functions and satisfaction levels were adversely affected in females with OSAS. Therefore, sexual functions and sexual satisfaction should be taken into account in the evaluation of female sexual health.

Keywords: Female sexual dysfunction, female sexual satisfaction, obstructive sleep apnea.

\section{Gíiș}

Obstruktif uyku apne sendromu (OUAS) uyku esnasında solunumun tekrarlayıcı bir şekilde parsiyel veya tamamen durmasıyla karakterize bir tablodur. ${ }^{[1]}$ OUAS oksijen seviyesinin azalmasına, uyku bölünmesine ve gündüz uykusunun artmasına sebep olarak kardiyovasküler mortalite ve morbiditenin artmasına, nörobilişsel yetilerin olumsuz etkilenmesine neden olur. ${ }^{[2]} \mathrm{Bu}$ kadar önemli olan 
bu tablonun orta yaşlı erkeklerin \%4'ünü ve kadınların $\% 2$ 'sini etkilediği tespit edilmiş̧ ${ }^{[3,4]}$ olmasına rağmen aslında orta-ağır OUAS olan kadınların \%93'ünün OUAS tanısı almadığı klinik bir çalışmada gösterilmiştir. ${ }^{[5]}$

Yaşam kalitesini olumsuz etkileyen ${ }^{[6]}$ OUAS' nin erkeklerde erektil disfonksiyona (ED) neden olduğu; OUAS tedavisi ile ED'nin düzeldiği 1970'li yıllardan beri bilinmektedir. [7-11] Erkeklerin aksine kadınlarda OUAS’nin kadın cinsel sağlığı üzerine etkisini inceleyen çok az çalışma vardır. ${ }^{[2,12-}$ ${ }^{14]} \mathrm{Bu}$ çalışmaların sonuçları da bir biri ile net olarak uyuşmamaktadır. Ek olarak bu çalışmaların tümünde sadece kadınların cinsel fonksiyonları araştırılmış olup OUAS’nin kadın cinsel sağlığının önemli bir parçası olan kadın cinsel memnuniyeti üzerine etkisi araştırılmamıştır.

Bu çalışmada OUAS’nin mevcudiyeti ve şiddetinin kadın cinsel fonksiyonuna ve cinsel memnuniyet üzerine etkisinin olup olmadığı, geçerliliği yapılmış ölçüm araçlarının kullanıldığı literatür ile incelendi.

\section{GEREÇ VE YÖNTEM}

Ocak-Haziran 2018 tarihleri arasında Eskişehir Devlet Hastanesi Uyku Bozukluğu Laboratuvarı'na horlama ve gece nefes tıkanıklığı nedeniyle başvuran, çalışmaya katılmayı kabul eden ve çalışma kriterlerine uyan kadın hastalar çalışmaya dahil edildi.

Çalışma dışı bırakılma kriterleri evli olmamak, yakın zamanlarda genital bir cerrahi operasyon geçirmiş olmak, alt üriner sistem hastalığına, herhangi bir psikiyatrik ve/veya nörolojik hastalığa, kronik kalp ve/veya solunum hastalıklarına, kronik böbrek hastalığına, herhangi bir onkolojik hastalığa sahip olmak ve alkolik olmak olarak belirlendi.

Çalışmaya dahil edilen kadın hastalara cinsel fonksiyonlarını değerlendirmek için Kadın Cinsel Fonksiyon İndeksi (KCFİ) ve cinsel memnuniyetlerini değerlendirmek için Kadın Cinsel Memnuniyet Ölçeği (KCMÖ) uygulandı.

Hastalara EEpworth Uykululuk Ölçeği (EUÖ) doldurulduktan sonra, tüm gece polisomnografi testi uygulandı ve hastalar Apne-Hipopne İndeksi'ne (AHİ) göre normal $(<5)$ hafif (5-15) ve orta-ciddi (>15) olarak üçe ayrıldı, OUAS saptanmayan kadın hastalar kontrol grubuna dahil edildi.

Kadın Cinsel Fonksiyon İndeksi 19 maddeden oluşan kadınlarda cinsel fonksiyon bozukluğunu değerlendiren; istek, uyarılma, lubrikasyon, orgazm, cinsel memnuniyet ve ağrı olmak üzere altı 6 ayrı başlıktan oluşan bir ölçektir. En düşük puan 2 ve en yüksek puan ise 36'dır. Yüksek puan daha iyi fonksiyon anlamına gelmektedir. Wiegel ve ark.'nın ${ }^{[15]}$ yaptıkları çalışmaya göre KCFİ skorunun 26,55 altında olması ise cinsel işlev bozukluğu (disfonksiyon) olduğunu göstermektedir. Ölçeğin geçerlik güvenirlik çalışması Rosen ve ark. ${ }^{[16]}$ tarafından yapılmış, Türkçe geçerlik ve güvenirlik analizi Aygin ve Eti Aslan ${ }^{[17]}$ tarafından yapılmıştır.

Kadın Cinsel Memnuniyet Ölçeği kadın cinsel memnuniyetini değerlendirmek için 2005 yılında Meston ve Trampnell[ ${ }^{[18]}$ tarafından geliştirilmiş 30 maddelik bir ölçektir. Ölçek memnuniyet, iletişim, uyumluluk, endişe (ilişki ile ilgili) ve endişe (kişisel) başlıkları adı altında toplam beş alt boyuttan oluşmaktadır. Ölçeğin toplam puanı ise Memnuniyet+İletişim+Uyumluluk+ (İlişkisel Endişe+Kişisel Endişe/2) formülü kullanılarak hesaplanmaktadır. Puan aralığı 30-150 puan olan ve kesme noktası bulunmayan ölçeğin yorumlanması, elde edilen skor ne kadar yüksek olursa cinsel memnuniyetin o kadar iyi olduğu şeklinde yapılır. Ölçeğin Türkçe geçerlik ve güvenirlik analizi 2014 yılında Abalı tarafında yapılmıştır. ${ }^{[19]}$

İstatistiksel analiz SPSS (versiyon 12.0, SPSS Inc., Chicago, IL, USA) kullanılarak yapıldı. Veriler ortalama \pm standart sapma olarak tanımland. Mann-Whitney U-test ve Kruskal-Wallis test gruplar arasında medianları değerlendirmek için, Pearson korelasyon testi ile KCFİ ve alt parametreleri ile KCMÖ ve alt parametreleri arasındaki ilişkiyi göstermek için kullanıldı. Bütün analizler sonucunda istatistiksel anlamlılık için $\mathrm{p}<0,05$ olması esas alındı.

\section{BULGULAR}

Ocak-Haziran 2018 tarihleri arasında Eskişehir Devlet Hastanesi Uyku Laboratuvarı'na horlama ve gece nefes t1kanıklığı nedeniyle başvuran 280 kadın hastaya polisomnografi testi uygulandi. Bu hastalardan 120'sinde OUAS saptanmadı. Çalışmaya katılmaya kabul eden ve kriterlere uyan 18 hasta kontrol grubu (grup 1) olarak kabul edildi. OUAS saptanan 160 hastadan çalışmaya katılmayı kabul eden ve kriterlere uyan 24 hasta Apne-Hipopne İndeksi'ne (AHİ) göre hafif $(\mathrm{AHI} \leq 15)$ ve orta-ciddi $(\mathrm{AHI}>15)$ olmak üzere ikiye ayrıldı. Hafif grupta (grup 2) 8, orta-ağır grupta (grup 3) 16 hasta olduğu tespit edildi.

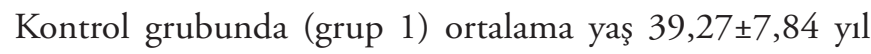
iken grup 2 ve 3'ün sırası ile ortalama yaşı $44 \pm 6,27$ ve $41,81 \pm 4,57$ yll bulundu (Tablo 1). Bu fark istatistiksel olarak anlamlı değil iken ( $\mathrm{p}=0,166)$ grup 1'in Vücut Kitle İndeksi (VKİ) her iki gruba göre istatistiksel olarak daha az saptandı $(\mathrm{p}=0,009)$. Beklenildiği gibi grup 2 ve 3'ün polisomonograkik bulguları ile EUÖ skorları, uyku verimliliği dişında grup 1 e göre istatistiksel olarak anlamlı olacak şekilde farklıdır. 
Tablo 1. Çalışmaya katılanların demografik, kişisel ve polisomnografik özellikleri

\begin{tabular}{lcccc}
\hline & Grup 1 & Grup 2 & Grup 3 & $p^{*}$ \\
\hline Yaş & $39,27 \pm 7,84$ & $44 \pm 6,27$ & $41,81 \pm 4,57$ & 0,166 \\
VKi & $30,38 \pm 4,87$ & $35,75 \pm 7,08$ & $36,68 \pm 6,2$ & $0,009 * *$ \\
Evlilik süresi & $18,77 \pm 8,64$ & $26,37 \pm 3,46$ & $22,87 \pm 4,54$ & $0.04 * *$ \\
Doğum sayısı & $2,05 \pm 1,05$ & $2,5 \pm 0,75$ & $2.25 \pm 1$ & 0.460 \\
EUÖ & $3,27 \pm 2,94$ & $5,25 \pm 2,12$ & $11,56 \pm 2,96$ & $p<0,001$ \\
AHI & $5,66 \pm 2,49$ & $16,5 \pm 2,97$ & $0<0,001$ \\
UV & $88,72 \pm 7,59$ & $85,5 \pm 7,28$ & $83,68 \pm 26,63$ & 0,113 \\
SaO2 <\%90 olduğu & $6,66 \pm 21.15$ & $35,12 \pm 37,84$ & $162,37 \pm 165,71$ & $p<0,001$ \\
hipopne sayısı & & & \\
Ortalama SaO2 (\%) & $95,00 \pm 1,08$ & $92,87 \pm 2,94$ & $0,18 \pm 6,13$ & $p<0,001$ \\
En düşük SaO2 (\%) & $90,94 \pm 1,98$ & $84 \pm 6,21$ & $78,75 \pm 9,56$ & $p<0,001$ \\
\hline
\end{tabular}

VKi: vucüt kitle indeksi; EUÖ: Epworth Uykululuk Ölçeği; AHi: Apne-hipopne İndeksi; UV: Uyku verimliliği (Hastanın uyuduğu sürenin yatakta geçen süreye oranı)

${ }^{*}$ Kruskal Wallis testi, ${ }^{* *} p<0,05$

Tablo 2. Katılımcıların kadın cinsel fonksiyon indeksi toplam ve alt parametre puanları

\begin{tabular}{lccccccc}
\hline KCFi & Grup 1 & Grup 2 & Grup 3 & $P^{* a}$ & $P^{* * b}$ & $P^{* * c}$ & $P^{* * d}$ \\
\hline İstek & $3 \pm 0,94$ & $2,55 \pm 1,23$ & $2,55 \pm 1,10$ & 0.300 & 0,126 & 0,429 & 0,976 \\
Uyarılma & $4,53 \pm 2,42$ & $2,81 \pm 2,6$ & $3,9 \pm 2,77$ & 0,268 & 0,443 & 0,129 & 0,320 \\
Lubrikasyon & $2,1 \pm 0,79$ & $1,46 \pm 0,70$ & $2,11 \pm 1,01$ & 0,123 & 0,721 & 0,09 & 0,061 \\
Orgazm & $3,22 \pm 1,69$ & $2,75 \pm 1,37$ & $3,25 \pm 1,73$ & 0,739 & 0,932 & 0,531 & 0,490 \\
Memnuniyet & $3,13 \pm 1,75$ & $3,15 \pm 1,42$ & $3,65 \pm 1,94$ & 0,563 & 0,365 & 0,935 & 0,417 \\
Ağrı & $10,05 \pm 3,63$ & $7,37 \pm 4,17$ & $9,5 \pm 5,04$ & 0,409 & 0,959 & 0,216 & 0,264 \\
Toplam & $19,64 \pm 7,78$ & $15,87 \pm 8,34$ & $19,08 \pm 9,56$ & 0,449 & 0,959 & 0,238 & 0,291 \\
\hline
\end{tabular}

*Kruskal Wallis testi, **Mann Whitney $\mathrm{U}$ test

a Her 3 grup karşılaştırıldığında

b Grup 1 ve 3 karşılaştıııldığında

c Grup 1 ve 2 karşılaştırıldığında

d Grup 2 ve 3 karşılaştııldığında

Tablo 3. Kadın cinsel fonksiyon indeksi toplam puanlarına göre katılımcılardaki cinsel işlev bozukluğu sıklığı

\begin{tabular}{lccccccc}
\hline & & Grup 1 & Grup 2 & Grup 3 & $p^{* a}$ & $p^{* b}$ & $p^{* c}$ \\
\hline Cinsel İşlev & & $N(\%)$ & $N(\%)$ & $N(\%)$ & & & \\
Bozukluğu & yok & $7(38,9)$ & $3(37.5)$ & $7(43.8)$ & \multirow{2}{*}{0,942} & 0,774 & 0,946 \\
\hline
\end{tabular}

*Ki kare testi

a Her 3 grup karşılaştırıldığında

b Grup 1 ve 3 karşılaştıııldı̆̆ında

c Grup 1 ve 2 karşıllaştırıldı̆̆ında

d Grup 2 ve 3 karşılaştıııldığında

Tüm hastaların KCFİ doldurduktan sonra elde ettikleri toplam puanları grup 1 için $19,64 \pm 7,78$, grup 2 için $15,87 \pm 8,34$ ve grup 3 için 19,08 $\pm 9,56$ bulundu (Tablo 2 ). Toplam puanlar istatistiksel olarak karşılaştırıldıklarında anlamlı bir fark saptanmadı $(\mathrm{p}>0,05)$. Aldıkları toplam puanlara göre grup 1'de cinsel işlev bozukluğu sıkllğı $\% 61,1$ iken grup 2 ve 3 de bu sıklık sırasıyla $\% 62,5$ ve $\% 56,3$ tespit edilmiş; hem 3 grup birlikte hem de ayrı ayrı birbiriyle karşılaştırıldıklarında cinsel işlev bozukluğu sıklığı açısından istatistiksel bir fark saptanmadı (Tablo 3). KCFI alt parametre puanları karşılaştırıldığında ise yine her 3 grubun alt parametre puanları arasında istatistiksel olarak anlamlı bir fark saptanmadı $(\mathrm{p}>0,05)$.

Çalışmaya dahil edilen hastaların KCMÖ doldurduktan sonra elde ettikleri puanlar grup 1 için $76,11 \pm 18,97$, grup 2 için $68,5 \pm 18,59$ ve grup 3 için $80,65 \pm 18,03$ olarak tespit edildi (Tablo 4). Toplam puanlar ve alt parametre puanları hem 3 grup birlikte hem de ayrı ayrı birbiriyle karşılaştırıldıklarında istatistiksel olarak anlamlı bir fark bulunamadı. 
Tablo 4. Kadın cinsel memnuniyet ölçeği toplam ve alt parametre puanları

\begin{tabular}{lccccccc}
\hline KCMÖ & Grup 1 & Grup 2 & Grup 3 & $p^{* a}$ & $p^{* *} b$ & $p^{* *} c$ & 0,238 \\
\hline Memnuniyet & $18,33 \pm 6$ & $15,37 \pm 5,6$ & $18,87 \pm 5,59$ & 0,335 & 0,851 & 0,153 \\
Iletişim & $20,44 \pm 5,02$ & $17,37 \pm 5,8$ & $19 \pm 6,03$ & 0,458 & 0,403 & 0,285 & 0,569 \\
Uyumluluk & $19,50 \pm 5,96$ & $19 \pm 5,8$ & $21,56 \pm 5,41$ & 0,486 & 0,347 & 0,765 & 0,320 \\
Endişe & $20,94 \pm 5,94$ & $19,25 \pm 5,75$ & $21,62 \pm 6,18$ & 0,693 & 0,798 & 0,531 & 0,417 \\
(ilişki ile ilgili) & $21,50 \pm 6,54$ & $19,87 \pm 6,68$ & $22,43 \pm 6,47$ & 0,642 & 0,670 & 0,605 & 0,350 \\
Endişe (Kişisel) & $76,11 \pm 18,97$ & $68,5 \pm 18,59$ & $80,65 \pm 18,03$ & 0,277 & 0,422 & 0,338 & 0,120 \\
Toplam & & & & & &
\end{tabular}

* Kruskal Wallis testi, ** Mann Whitney $\mathrm{U}$ test

a Her 3 grup karşılaştıııldığında

b Grup 1 ve 3 karşılaştırıldığında

c Grup 1 ve 2 karşıış̧trııldı̆̆ında

d Grup 2 ve 3 karşılaştırıldığında

Tablo 5. KCFi ile KCMÖ toplam ve alt parametre puan ilişkisi*

\begin{tabular}{|c|c|c|c|c|c|c|}
\hline & Memnuniyet & Iletişim & Uyumluluk & $\begin{array}{c}\text { Endişe } \\
\text { (Iliş̧ki ile ilgili) }\end{array}$ & Endişe (Kişisel) & Toplam \\
\hline İstek & $0,574(* * *)$ & $0,652(* * *)$ & $0,526(* * *)$ & 0,222 & 0,321 & $0,508(* *)$ \\
\hline Uyarılma & $0,614(* * *)$ & $0,566(* * *)$ & $0,481(* *)$ & 0,176 & 0,324 & $0,487(* *)$ \\
\hline Lubrikasyon & $0,469(* *)$ & $0,468(* *)$ & 0,353 & 0,095 & 0,244 & 0,379 \\
\hline Orgazm & $0,614(* * *)$ & $0,637(* * *)$ & $0,502(* *)$ & 0,137 & 0,254 & $0,496(* *)$ \\
\hline Memnuniyet & $0,630(* * *)$ & $0,660(* * *)$ & $0,412(* *)$ & 0,138 & 0,289 & $0,486(* *)$ \\
\hline Ağrı & $0,433(* *)$ & $0,582(* * *)$ & $0,462(* *)$ & 0,171 & 0,266 & $0,419(* *)$ \\
\hline Toplam & $0,615(* * *)$ & $0,649(* * *)$ & $0,457\left({ }^{* *}\right)$ & 0,077 & 0,209 & $0,473(* *)$ \\
\hline
\end{tabular}

* Pearson korelasyon analizi

$* * p<0.05$

$* * * \mathrm{P}<0.001$

Polisomnografi sonrası OUAS tanısı konan grup 2 ve grup 3 'teki toplam 24 hastanın KCFİ toplam ve alt parametre puanları ile KCMÖ toplam ve alt parametre puanları korelasyon analizi ile değerlendirildiğinde (Tablo 5) KCMÖ'nin her iki endişe parametresi haricinde iki ölçeğin hem toplam hem de alt parametre puanları arasında istatistiksel olarak birbiri ile ilişkili olduğu saptandı.

\section{TARTIȘMA}

Kadın cinsel işlev döngüsü istek, uyarılma, lubrikasyon ve orgazm evrelerinden oluşur. Bu evrelerde meydana gelebilecek problemler kadınlarda CİB'ye neden olur. Kadınların yaşam kalitesini olumsuz etkileyen CİB'nin birçok faktörü olup vasküler, nörojenik, hormonal mekanizmalar CİB'nin meydana gelmesinde rol oynamaktadır. ${ }^{[20]}$

Yurtdışında yapılan prevelans çalışmalarında toplumda kadınların \%43,1 ile \%68,8'nin CİB'den etkilendiği saptanmış olup ${ }^{[21,22]}$ ülkemizde Çayan ve ark. tarafından yaşlara göre yapılan prevalans çalışmasında CİB görülme sıklı̆̆ $18-27$ yaş arası $\% 21,7,28-37$ yaş arası \%25,5, 38-47 yaş arası $\% 53,5,48-57$ yaş arası $\% 65,9$ ve $58-67$ yaş arası $\% 92,9$ olarak bulunmuştur. ${ }^{[23]}$
Başta kardiyovasküler hastalıklar, diabetes mellitus ve hipertansiyon olmak üzere, kronik hastalıkların kadınlarda CİB'ye yaygın bir şekilde neden olabileceği gösterilmiştir. ${ }^{[24,25]}$ Her ne kadar bizim çalışmamızda kontrol grubu ile diğer 2 çalışma grubu arasında CİB görülme sıklığı arasında istatistiksel fark saptanamamış ise de; OUAS'nin kadınlarda CİB'na neden olabileceği gösterilmiştir [1,2,12-14,26,27] OUAS multifaktöryel mekanizmalar sonucunda CİB'ye neden olduğu düşünülmekle beraber ${ }^{[13]}$ OUAS kaynaklı endotel disfonksiyonunun patofizyolojiden önemli rol oynadığı düşünülmektedir. ${ }^{[2]}$

OUAS şiddeti ile CİB ilişkisini araştırmalar sonucunda netlik kazanamamıştır. Literatürde OUAS şiddeti ile CİB ilişkisini ilk kez Köşeoğlu ve ark. ülkemizde araştırmışlar ve bu çalışmanın sonucunda OUAS'nin şiddeti arttıkça CİB'nin arttığını göstermişlerdir. ${ }^{[12]}$ Fanfulla ve ark. da yaptıkları çalışmada benzer sonuca ulaşmışlar ve nokturnal hipoksinin CİB şiddeti ile ilişkili olduğunu öne sürmüşlerdir. ${ }^{[1]}$ Stavaras ve ark. ise hem premenopozal hem de postmenopazal kadınlarda OUAS şiddetlendikçe CİB şiddetinin arttığını tespit etmişlerdir. ${ }^{[26]} \mathrm{Bu}$ sonuçlarının aksine Petersenve ark. ${ }^{[14]}$ ile Önem ve ark. ${ }^{[2]}$ yaptıkları 
çalışmalarda OUAS'nin kadınlarda CİB'ye neden olduğu fakat OUAS şiddeti ile CİB şiddeti arasında bir ilişkinin olmadığı öne sürülmüşsür. Bizim çalışmamızda hafif şiddetli ile orta-ağır şiddetli OUAS hastalarımız karşılaştırıldığında her iki grup arasında CİB sıklı̆ğ arasında istatistiksel fark saptanmamış olup normal polisomnografiye sahip kadınlar ile OUAS saptanan hastaların CİB sıklığı açısından aralarında istatistiksel bir fark saptanmamışır. Kontrol grubumuzun ortalama yaş grubu 38-47 yıl olarak kabul edilirse bizim grubumuzdaki CİB sıklığı \%61,1 iken Çayan ve ark. ${ }^{[23]}$ bu yaş grubunda saptadıkları CİB sıklığına $(\% 53,5)$ göre daha yüksek olması; çalışmamızda çalışma ve kontrol grupları arasında fark saptanmamasına neden olduğu öngörüldü.

Bir cinsel ilişkideki pozitif ve negatif yönlerin bireyi etkilemesiyle ortaya çıan hise veya duyguya cinsel memnuniyet $(\mathrm{CM})$ denir. ${ }^{[28]}$ Genel yaşam kalitesi ${ }^{[29-31]}$ yaşanan ilişkiden duyulan memnuniyet ${ }^{[32]}$, o ilişkinin sıkıntısız bir şekilde ilerlemesi ${ }^{[33]}$ cinsel ilişki sıkl ${ }_{\text {ğğ }}{ }^{[34]}$ ve CİB'nin olmama${ }_{S 1}{ }^{[35,36]} \mathrm{CM}$ 'i etkileyen faktörlerdir. Kadın cinsel sağlığının önemli bir komponenti olan CM, bugüne kadar yapılan OUAS ile kadın cinsel sağlığı konulu çalışmalarda gereken önemi görememiştir. CM konusu sadece KCFİ ölçeğindeki 'memnuniyet' alt parametresi ile değerlendirilmiş olup literatürde ilk kez bu çalışmada OUAS'nin CM üzerine etkisi KCMÖ ile değerlendirilmeye çalışılmıştır. KCMÖ ile elde ettiğimiz sonuçlara göre çalısmamızda kontrol grubu ile diğer iki grup arasında toplam CM puanları arasında bir fark saptanamadığı gibi hafif ve orta-ciddi OUAS olan hastalar arasında da toplam puanlar arasında fark saptanmadı.

Kadınlarda cinsel fonksiyonun normal olması ile cinsel memnuniyet arasındaki ilişkinin paralel olduğu düşünülen genel bir kan ${ }^{[18,37,38]}$ olmakla beraber çalışmalar göstermektedir ki cinsel fonksiyonun normal olması her zaman cinsel memnuniyet ile paralel seyredebilen bir durum değildir. ${ }^{[39]}$ Amerika Birleşik Devletleri'nde yaşayan kadınların \%85 'i cinsel olarak memnun iken diğer ülkelerde bu oran $\% 42$ olarak tespit edilmiş ${ }^{[30,40]}$, cinsel memnuniyetin bu kadar yüksek olmasına rağmen yine bu ülkede kadınların en az \%43' ünün orgazm, istek ve lubrikasyonda bozukluk ile cinsel ilişki sırasında ağrı konularının en az birinde problem yaşadığı gösterilmiştir. ${ }^{[41]}$ Yine Ferenidou ve ark. yaptıkları çalışmada cinsel açıdan memnuniyetsiz olan kadınların hepsinde cinsel problem saptandığı gibi kendini cinsel memnun olarak gören kadınların \%81'inde de en az bir cinsel sorun bulunduğu gösterilmiştir. ${ }^{[42]}$ Cinsel problemin olmasından ziyade CİB yaşama stresinin de cinsel memnuniyetsizliğe neden olabileceği King ve ark. tarafından gösterilmiştir. ${ }^{[43]}$
Pujols ve ark. 2010 yılında kadın cinsel işlevi ile cinsel memnuniyet arasındaki ilişkiyi göstermek için planladıkları çalışmada cinsel fonksiyon bozukluğunu değerlendirmek için KCFİ, cinsel memnuiyeti göstermek için KCMÖ'yü kullanmışlardır. ${ }^{[39]} \mathrm{Bu}$ çalışmada cinsel fonksiyonun iyiliği ile CM arasında yakın bir korelasyon olduğu; KCFİ'nin ve KCFÖ’nün tüm alt parametrelerinin birbiri ile yakın ilişkili olduğu gösterilmiştir. Aynı ölçeklerin kullanıldığı bir başka çalışmada ise yine benzer sonuçlar elde edilmiştir. ${ }^{[18]}$ Cinsel fonksiyon bozukluğunu değerlendirmek için KCFİ; cinsel memnuniyeti değerlendirmek için KCMÖ’yü kullandığımız bu çalışmada yukarıda bahsedilen diğer iki çalışmaya benzer sonuçlar elde edilmiş olup CİB azaldıkça cinsel memnuniyetin arttığı saptanmıştır. Bu sonuca ek olarak KCFİ'nin tüm alt parametreleri'endişe' parametreleri hariç diğer KCMÖ parametreleri ile yakın ilişki içinde olduğu gösterilmiştir.

\section{SONUÇ}

Sonuç olarak OUAS kadın cinsel sağlığına olumsuz etkisi olan önemli bir sendromdur. Bu olumsuz etki daha çok kadın cinsel işlev fonksiyonu üzerinde gösterilmiş olup cinsel memnuniyet üzerine olan etkisi net olarak araştırılmamıştır. OUAS'nin cinsel memnuniyet üzerine etkisini gösterebilmek için daha geniş popülasyonlu çalışmalar planlanmalıdır.

\section{Hakem Değerlendirmesi \\ Dış bağımsız \\ Çıkar Çatışması \\ Yazarlar çıkar ilişkisi olmadığını beyan etmişlerdir. \\ Finansal Destek \\ Herhangi bir mali destek alınmamıştır.}

\section{Peer-review}

Externally peer-reviewed.

Conflict of Interest

No conflict of interest was declared by the authors.

Financial Disclosure

No financial disclosure was received.

\section{KAYNAKLAR}

1. Fanfulla F, Camera A, Fulgoni P, Chiovato L, Nappi RE. Sexual dysfunction in obese women: Does obstructive sleep apnea play a role? Sleep Med 2013;14:252-6. [CrossRef]

2. Onem K, Erol B, Sanli O, Kadioglu P, Yalin AS, Canik U, et al. Is sexual dysfunction in women with obstructive sleep apneahypopnea syndrome associated with the severity of the disease? A pilot study. J Sex Med 2008;5:2600-9. [CrossRef]

3. Young T, Palta M, Dempsey J, Skatrud J, Weber S, Badr S. The occurrence of sleep disordered breathing among middle-aged adults. N Engl J Med 1993;328:1230-5. [CrossRef]

4. Bixler EO, Vgontzas AN, Lin HM, Ten Have T, Rein J, Vela-Bueno A, Kales A. Prevalence of sleep-disordered breathing in women: effects of gender. Am J Respir Crit Care Med 2001;163:608-13. [CrossRef] 
5. Young T, Evans L, Finn L, Palta M. Estimation of the clinically diagnosed proportion of sleep apnea syndrome in middle-aged men and women. Sleep 1997;20:705-6. [CrossRef]

6. Finn L, Young T, Palta M, Fryback DG. Sleep-disordered breathing and self reported general health status in the Wisconsin sleep cohort study. Sleep 1998;21:701-6. [CrossRef]

7. Guilleminault C, Eldridge FL, Tilkian A, Simmons FB, Dement WC. Sleep apnea syndrome due to upper airway obstruction: a review of 25 cases. Arch Intern Med 1977;137:296-300. [CrossRef]

8. Teloken PE, Smith EB, Lodowsky C, Freedom T, Mulhall JP. Defining association between sleep apnea syndrome and erectile dysfunction. Urology 2006;67:1033-7. [CrossRef]

9. Goncalves MA, Guilleminault C, Ramos E, Palha A, Paiva T. Erectile dysfunction, obstructive sleep apnea syndrome and nasal CPAP treatment. Sleep Med 2005;6:333-9. [CrossRef]

10. Margel D, Cohen M, Livne PM, Pillar G. Severe, but not mild, obstructive sleep apnea syndrome is associated with erectile dysfunction. Urology 2004;63:545-9. [CrossRef]

11. Heruti R, Shochat T, Tekes-Manova D, Ashkenazi I, Justo D. Association between erectile dysfunction and sleep disorders measured by self-assessment questionnaires in adult men. J Sex Med 2005;2:543-50. [CrossRef]

12. Koseoglu N, Koseoglu H, Itil O, Oztura I, Baklan B, Ikiz AO, Esen AA. Sexual function status in women with obstructive sleep apnea syndrome. J Sex Med 2007;4:1352-7. [CrossRef]

13. Subramanian S, Bopparaju S, Desai A, Wiggins T, Rambaud C, Surani A. Sexual dysfunction in women with obstructive sleep apnea. Sleep Breath 2010;14:59-62. [CrossRef]

14. Petersen M, Kristensen E, Berg S, Giraldi A, Midgren B. Sexual function in female patients with obstructive sleep apnea. J Sex Med 2011;8:2560-8. [CrossRef]

15. Wiegel M, Meston C, Rosen R. The female sexual function index (FSFI): cross-validation and development of clinical cutoff scores. J Sex Marital Ther 2005;31:1-20. [CrossRef]

16. Rosen R, Brown C, Heiman J, Leiblum S, Meston C, Shabsigh R, et al. The Female Sexual Function Index (FSFI): a multidimensional self-report instrument for the assessment of female sexual function. J Sex Marital Ther 2000;26:191-208. [CrossRef]

17. Aygin D, Eti Aslan F. Kadın Cinsel İşlev Ölçeği'nin Türkçeye Uyarlaması. Turkiye Klinikleri J Med Sci 2005;25:393-9.

18. Meston C, Trapnell P. Development and Validation of a Five-Factor Sexual Satisfaction and Distress Scale for Women: The Sexual Satisfaction Scale for Women (SSS-W). J Sex Med 2005;2:66-81. [CrossRef]

19. Abalı S. Menstrüal siklus evrelerine göre kadında cinsel işlev özellikleri. İ. Ü Sağlık Bilimleri Enstitüsü Kadın Sağlığı ve Hastalıkları Hemşireliği AB, Doktora Tezi, İstanbul, 2014.

20. Berman JR, Bassuk J. Physiology and pathophysiology of female sexual function and dysfunction. World J Urol. 2002 Jun;20(2):111-8. [CrossRef]

21. Sidi H, Puteh SEW, Abdullah N, Midin M. The prevalence of sexual dysfunction and potential risk factors that may impair sexual function in Malaysian Women. J Sex Med 2007;4:31121. [CrossRef]

22. Shifren JL, Monz BU, Russo PA, Segreti A, Johannes CB. Sexual problems and distress in United States women: prevalence and correlates. Obstet Gynecol 2008;112:970-8. [CrossRef]

23. Cayan S, Akbay E, Bozlu M, Canbolat B, Acar D, Ulusoy E. The prevalance of female dyfunction and potential risk factors that may impair sexual function in Turkish women. Urol Int 2004;72:52-7.

\section{[CrossRef]}

24. Fatemi SS, Taghavi SM. Evaluation of sexual function in women with type 2 diabetes mellitus. Diab Vasc Dis Res 2009;6:38-9. [CrossRef]

25. Hiz O, Ediz L, Gülcü E, Tekeoglu I. Effects of Behçet’s Disease on Sexual Function and Psychological Status of Male Patients. J Sex Med 2011;8:1426-33. [CrossRef]

26. Stavaras C, Pastaka C, Papala M, Gravas S, Tzortzis V, Melekos M, et al. Sexual function in pre- and post-menopausal women with obstructive sleep apnea syndrome. Int J Impot Res 2012;24:22833. [CrossRef]

27. Yilmaz Z, Sirinocak PB, Voyvoda B, Ozcan L. Sexual Dysfunction in Premenopausal Women With Obstructive Sleep Apnea. Urol J 2017;14:5051-6. [CrossRef]

28. Lawrance K, Byers ES. Development of the interpersonal exchange model of sexual satisfaction in long term relationships. Can J Hum Sex 1992;1:123-8.

29. Apt C, Hurlbert D, Pierce A, White C. Relationship satisfaction, sexual characteristics and the psychosocial well-being of women. Can J Hum Sex 1996;5:195-210.

30. Laumann E, Palik A, Rosen R. Sexual dysfunction in the United States: Prevalence and predictors. JAMA 1999;281:537-44. [CrossRef]

31. Ventegodt S. Sex and the quality of life in Denmark. Arch Sex Behav 1998;27:295-307.

32. Byers ES. Relationship satisfaction and sexual satisfaction: A longitudinal study of individuals in long-term relationships. J Sex Res 2005;42:113-8. [CrossRef]

33. Sprecher S. Sexual satisfaction in premarital relationships: Associations with satisfaction, love, commitment, and stability. J Sex Res 2002;39:190-6. [CrossRef]

34. Brody S, Costa RM. Satisfaction (sexual, life, relationship, and mental health) is associated directly with penile-vaginal intercourse, but inversely with other sexual behavior frequencies. J Sex Med 2009;6:1947-54. [CrossRef]

35. Morokoff P, Gillilland R. Stress, sexual functioning, and marital satisfaction. J Sex Res 1993;30:43-53. [CrossRef]

36. Hurlbert D, Apt C, Rabehl S. Key variables to understanding female sexual satisfaction: An examination of women in nondistressed marriages. J Sex Marital Ther 1993;19:154-65. [CrossRef]

37. Offman A, Matheson K. Sexual compatibility and sexual functioning in intimate relationships. Can J Hum Sex 2005;14:31-9.

38. Trudel G. Sexuality and marital life: Results of a survey. J Sex Marital Ther 2002;28:229-49. [CrossRef]

39. Pujols Y, Meston C, Seal B. The Association Between Sexual Satisfaction and Body Image in Women. J Sex Med 2010;7(2Pt2):905-16. [CrossRef]

40. Mulhall J, King R, Glina S, Hvidsten K. Importance of and satisfaction with sex among men and women worldwide: Results of the global better sex survey. J Sex Med 2008;5:788-95. [CrossRef]

41. Laumann EO, Gagnon JH, Michael RT, Michaels S. The social organization of sexuality: Sexual practices in the United States. Chicago: The University of Chicago Press; 1994. pp.364-75.

42. Ferenidou F, Kapoteli V, Moisidis K, Koutsogiannis I, Giakoumelos A, Hatzichristou D. Presence of a sexual problem may not affect women's satisfaction from their sexual function. J Sex Med 2008;5:631-9. [CrossRef]

43. King M, Holt V, Nazareth I. Women's views of their sexual difficulties: Agreement and disagreement with clinical diagnoses. Arch Sex Behav 2007;36:281-8. [CrossRef] 